\title{
ORIENTASI KEBAHAGIAAN SISWA SMA, TINJAUAN PSIKOLOGI INDIGENOUS PADA SISWA LAKI-LAKI DAN PEREMPUAN
}

\author{
Putri Oetami \& Kwartarini Wahyu Yuniarti \\ Center for Indigenous \& Cultural Psychology \\ Fakultas Psikologi \\ Universitas Gadjah Mada \\ Jl. Humaniora No. 1 Bulaksumur Yogyakarta 55281 \\ kwartarini_yuniarti@yahoo.com.
}

\begin{abstract}
The purpose of this study was to analyze the happiness orientation of boys and girls. A number of 459 high school students in Yogyakarta and Ciamis filled out questionnaire with open-ended questions developed by Kim and information about the data itself. The analysis method in this study used a combination of qualitative and quantitative methods with indigenous psychology approach, an approach from the perspective of the local culture, was used to analyze the data response from open questions, so the original data was obtained in the reality of Indonesia itself, so every phenomenon was seen in context, presented and interpreted in relative terms based on the cultural, ecological, and where the phenomenon took place. Categorization responses were analyzed by cross tabulation statistical methods with the sex of respondents. The results showed that there was no significant difference in happiness boys and girls. Events that made the most happy for the boys was the event associated with achievement, spirituality, friends, and leisure time, whereas for girls was associated with family, love and be loved, as well as money.
\end{abstract}

Keywords: Gender, Happiness, Indigenous Psychology, Youth.

\begin{abstract}
Abstrak
Tujuan penelitian ini adalah untuk menganalisis orientasi kebahagiaan remaja laki-laki dan perempuan. Sejumlah 459 siswa SMA di Yogyakarta dan Ciamis mengisi kuesioner dengan pertanyaan terbuka yang dikembangkan oleh Kim dan informasi mengenai data diri. Analisis yang digunakan dalam penelitian ini menggunakan kombinasi metode kualitatif dan kuantitatif, dengan pendekatan indigenous psychology, pendekatan
\end{abstract}


yang dilihat dari sudut pandang budaya lokal, yang memungkinkan untuk melihat setiap fenomena dipandang sesuai dengan konteks terkait. Respon dikategorisasikan berdasarkan persamaan tema, kemudian frekuensi respon dalam kelompok kategorinya ditabulasi silang dengan jenis kelamin responden. Hasil penelitian menunjukkan bahwa dari statistik dekriptif tidak ada perbedaan yang signifikan kebahagiaan remaja laki-laki dan perempuan. Peristiwa yang membuat paling bahagia bagi remaja laki-laki adalah peristiwa yang berhubungan dengan prestasi, spiritualitas, teman, dan waktu luang, sedangkan bagi remaja perempuan adalah peristiwa yang berhubungan dengan keluarga, mencintai dan dicintai, serta uang.

Kata kunci : Indigenous Psychology, Jenis kelamin, Kebahagiaan, Remaja.

\section{Pendahuluan}

Kebahagiaan adalah dambaan setiap orang, seperti yang diinginkan oleh seorang remaja.Kebahagiaan adalah keadaan emosi positif yang didefinisikan secara subjektif oleh setiap orang (Snyder \& Lopez, 2006). Konsep kebahagiaan terkadang masih menjadi misteri. Kebahagiaan termasuk dalam psikologi positif. Kebahagiaan agak sulit untuk diartikan karena cakupannya yang luas dan dalam (Strongman, 2005).

Shahar (2007) memberikan tips untuk bertanya dengan kata bantu " $w h y$ " untuk mendapatkan tolok ukur kebahagiaan, seperti mengapa seseorang ingin kaya, mobil baru, terkenal, dan sukses? Jawabannya akan bermuara karena yang bersangkutan ingin bahagia. Apabila diteruskan dengan pertanyaaan alasan seseorang ingin bahagia, maka tidak ada jawaban lain yang lebih baik daripada memang tujuan seseorang adalah hidup bahagia. Semua tolok ukur baik kekayaan material, popularitas, kepuasan spiritual maupun emosional hanya akan bermuara ke satu kata yaitu kebahagiaan.

Penelitian tentang kebahagiaan sangat penting dilakukan karena kebahagiaan merupakan cita-cita tertinggi yang selalu ingin diraih oleh semua manusia dalam tindakannya (Ryff, 1989). Kebahagiaan juga menjadi penghalang stres (Argyle, 2001). Lebih lanjut, Argyle (2001) menjelaskan bahwa kejadian hidup yang positif mengurangi keputusasaan dan depresi, tetapi hanya jika mereka memiliki atribusi yang positif. Dengan demikian dapat disimpulkan bahwa kebahagiaan akan membawa individu menjadi individu yang memiliki jiwa yang sehat.

Penelitian yang dilakukan oleh Jersild (dalam Mappiare, 1982) menunjukkan adanya keragaman hal-hal yang menyebabkan seseorang berbahagia. Bagi remaja 
usia 15-18 tahun, sumber-sumber kebahagiaan yang mendapatkan frekuensi tertinggi terdiri dari: (1) pergi rekreasi ramai-ramai, misalnya mengunjungi cagar alam;(2) mencapai peningkatan diri, berhasil di sekolah, ada kesempatan memperoleh pendidikan, serta ada rasa penting dalam jabatan;(3) memperoleh hubungan baik dengan orang lain, bersahabat karib, dan mendapatkan teman yang pasti;(4) dalam suasana sport, permainan-permainan, dan bersepeda; serta(5) merasa diri bermanfaat bagi orang lain.

Menurut Compton (2005), tidak ada perbedaan kebahagiaan antara laki-laki dan perempuan. Tidak ada yang lebih bahagia antara laki-laki dan perempuan, namun terdapat penyebab kebahagiaan yang berbeda pada dua jenis kelamin (Argyle, 2001). Laki-laki lebih dipengaruhi pekerjaaan, kepuasan ekonomi, dan diri mereka sendiri. Adapun wanita lebih dipengaruhi oleh anak-anak mereka dan kesehatan keluarganya. Di Taiwan ditemukan bahwa kebahagiaan laki-laki Taiwan tergantung pada kepuasan kerja, sedangkan wanita tergantung pada kepuasan dan kebahagiaan keluarganya.

Mengingat pentingnya kebahagiaan bagi individu, maka timbul pertanyaan mengenai peristiwa yang membuat remaja merasa paling bahagia dalam hidupnya dan ada tidaknya perbedaan orientasi kebahagiaan pada remaja laki-laki dan perempuan.Berdasarkan kedua pertanyaan tersebut maka akan diketahui orientasi kebahagiaan pada remaja, laki-laki dan perempuan. Peneliti menggunakan pendekatan Indigenous Psychology, yaitu pendekatan yang dilihat dari sudut pandang budaya lokal, agar data yang diperoleh asli dalam realitas Indonesia sendiri, sehingga setiap fenomena dipandang menurut konteks, dipapar, serta ditafsirkan secara relatif berdasarkan situasi budaya dan ekologi tempat fenomena berlangsung.Diharapkan, hasil penelitian dapat menambah kajian teori tentang kebahagiaan dan pemahaman kepada para orangtua yang memiliki anak usia remaja, berbagai instansi pendidikan dan para pengajar yang memiliki siswa usia remaja, serta bagi remaja sendiri untuk lebih memahami dirinya. Hasil penelitian dapat digunakan oleh pihak-pihak terkait dalam menentukan langkah-langkah untuk meraih kebahagiaan.

\section{Metode Penelitian}

Responden dalam penelitian ini adalah remaja laki-laki dan perempuan siswa Sekolah Menengah Atas (SMA) di Yogyakarta dan SMA di Ciamis. Peneliti menggunakan jenjang pendidikan SMA dikarenakan siswa SMA adalah usia remaja yaitu berusia antara 13-18 tahun (Hurlock, 2004), serta pada masa itu telah memasuki fase menghayati nilai-nilai kehidupan. Jumlah responden penelitian seluruhnya 
berjumlah 467 orang. Namun, delapan responden mengisi kuisioner dengan tidak lengkap, sehingga tidak dapat dianalisis lebih lanjut. Jadi, jumlah responden pada penelitian ini adalah 459 orang, terdiri dari 190 siswa laki-laki dan 269 siswa perempuan.

Data mengenai peristiwa yang membuat paling bahagia pada individu dikumpulkan dengan menggunakan kuesioner dengan pertanyaan terbuka atau open ended questionnaires yang merupakan hasil adaptasi dari kuesioner yang dikembangkan oleh Kim (2009). Kuesioner tersebut merupakan salah satu instrumen dari metode Indigenous Psychology yang digunakan untuk mempelajari perilaku sesuai dengan konteks budaya lokal (Kim \& Berry, 1993). Pertanyaan yang diajukan adalah untuk mengungkap mengenai peristiwa yang membuat remaja merasa paling bahagia.

Data yang diperoleh dianalisis dengan menggunakan tabulasi silang, yaitu dengan memasukkan data data kuantitatif yang sudah diolah sebelumnya dan data kualitatif yang sudah dikuantitatifkan dalam SPSS (Statistic Package for Social Sciences) for windows version 17.0.

\section{Hasil dan Pembahasan}

Untuk mendapatkan gambaran mengenai peristiwa yang membuat remaja merasa paling bahagia, maka kepada responden diberikan pertanyaan terbuka sebagai berikut: "Tulislah peristiwa yang membuatmu paling bahagia! Jawaban responden terhadap pertanyaan ini sangat bervariasi. Hal ini terlihat dari kategori besar jawaban responden yang ditampilkan pada grafik 1 .

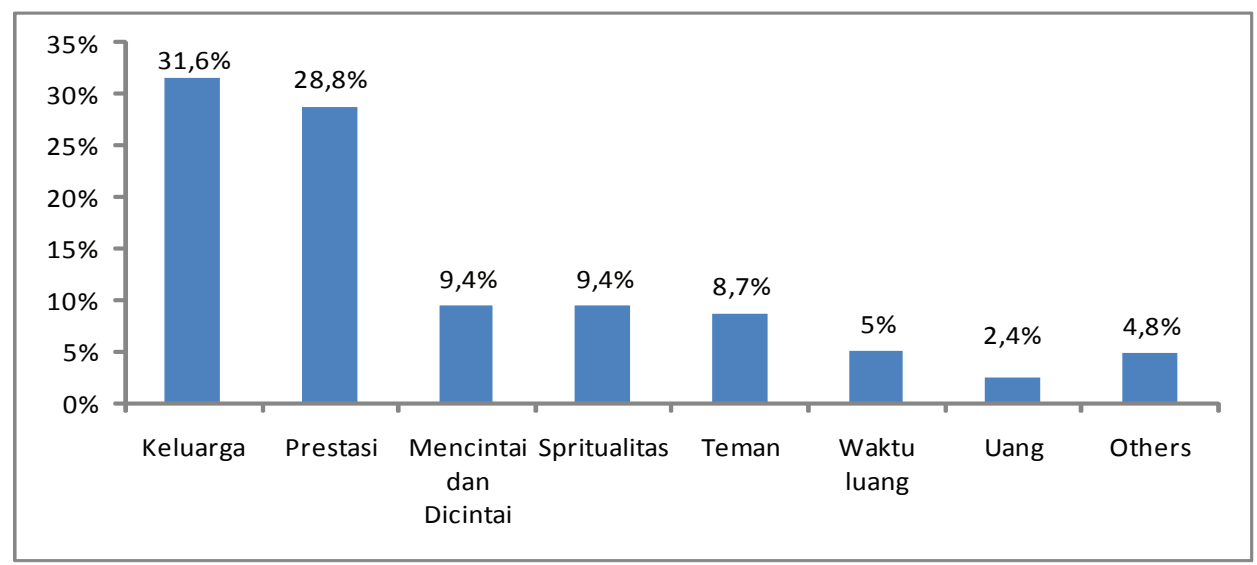

Gambar 1. Peristiwa yang Membuat Responden Bahagia 
Grafik di atas menunjukkan bahwa secara keseluruhan peristiwa yang membuat paling bahagia adalah peristiwa yang berhubungan dengan keluarga $(31,6 \%)$,selanjutnya diikuti oleh alasan peristiwa prestasi sebesar 28,8\%. Respon lain menetapkan bahwa mencintai dan dicintai sebagai peristiwa yang membuat bahagia sebesar $9,4 \%$, spiritualitas $9,4 \%$, teman $8,7 \%$, waktu luang $5 \%$, mendapatkan uang $2,4 \%$, serta jawaban-jawaban lain sebesar $4,8 \%$ masuk ke dalam kategori "others".

\section{Keluarga}

Kategori besar keluarga terdiri dari kategori-kategori kecil yang meliputi kategori dicintai orangtua, kebersamaan dengan keluarga, bertemu ibu/ayah, liburan dengan kelurga, membahagiakan keluarga, membahagiakan orangtua, membanggakan orangtua, membantu keluarga, memiliki keluarga harmonis dan bahagia, memiliki orangtua yang baik, mempunyai adik, serta selamat dari musibah.

\section{Prestasi}

Kategori prestasi meliputi kategori berguna bagi orang lain, berprestasi, cita-cita tercapai, diterima di sekolah yang diinginkan, juara, keinginan tercapai, lulus, memecahkan masalah, mendapat hadiah, mendapat rangking bagus, menemukan sesuatu, mengalahkan orang lain, nilai bagus dan sukses.

\section{Mencintai dan dicintai}

Kategori mencintai dan dicintai terdiri dari kategori kecil bertemu orang spesial, cinta, dicintai, diperhatikan, diterima orang lain, kebersamaan dengan orang dekat, kebersamaan dengan orang yang dicintai, memaafkan, serta ulang tahun.

\section{Spiritualitas}

Kategori spiritualitas merupakan kumpulan dari kategori fisik yang baik, hidup, lahir dan kelahiran, serta spiritualitas

\section{Teman}

Kategori teman meliputi kategori kecil bertemu orang spesial, kebersamaan dengan teman, memiliki pacar, serta memiliki teman. 


\section{Waktu luang}

Kategori waktu luang terdiri dari kategori bercanda, bermain, liburan, serta menonton film.

\section{Uang}

Kategori besar uang, merupakan kategori yang terdiri dari satu kategori kecil yaitu kategori uang tersebut sendiri.

\section{Lain-lain ( others )}

Kategori "others" merupakan kategori besar yang terdiri dari jawabanjawaban yang tidak sesuai dengan kategori yang sudah ada seperti kategori kecil beruntung, bisa makan, kebebasan, membahagiakan diri sendiri, serta mendapatkan kejutan dan jawaban yang tidak mewakili pertanyaan seperti irrelevant answer serta missing atau responden tidak menjawab pertanyaan dari aitem pertama.

Peneliti menggunakan informasi keadaan diri responden berupa jenis kelamin untuk mengetahui peristiwa yang membuat paling bahagia responden menurut jenis kelaminnya. Tabel 1 di bawah ini merupakan data tabulasi silang yang memperlihatkan peristiwa-peristiwa yang membuat paling bahagia oleh siswa laki-laki dan perempuan:

Tabel 1.

Tabulasi silang kategori dengan jenis kelamin

\begin{tabular}{llcccccc}
\hline \multirow{2}{*}{ No } & \multirow{2}{*}{ Kategori } & \multicolumn{2}{c}{ Laki-laki } & \multicolumn{2}{c}{ Perempuan } & \multicolumn{2}{c}{ Total } \\
& & $\mathrm{N}$ & $\%$ & $\mathrm{~N}$ & $\%$ & $\mathrm{~N}$ & $\%$ \\
\hline 1 & Keluarga & 51 & 26,8 & 94 & 34,9 & 145 & 31,6 \\
2 & Prestasi & 61 & 46,2 & 71 & 53,8 & 132 & 28,8 \\
3 & Mencintai dan Dicintai & 12 & 27,9 & 31 & 72,1 & 43 & 9,4 \\
4 & Spiritualitas & 21 & 48,8 & 22 & 51,2 & 43 & 9,4 \\
5 & Teman & 18 & 46,2 & 21 & 53,8 & 39 & 8,5 \\
6 & Waktu Luang & 12 & 52,2 & 11 & 47,8 & 23 & 5 \\
7 & Uang & 3 & 27,3 & 8 & 72,7 & 11 & 2,4 \\
8 & Others & 11 & 50 & 11 & 50 & 22 & 4,8 \\
& Pearson's $\chi 2$ & & & 0.161 & & & \\
\hline
\end{tabular}


Analisis menunjukkan bahwa tidak ada perbedaan yang signifikan ( $\mathrm{p}>0.05)$ antara peristiwa yang membuat bahagia dengan jenis kelamin. Data menunjukkan bahwa terdapat delapan peristiwa yang dirangkum dalam kategorisasi besar yang membuat remaja bahagia, termasuk jawaban "others". Namun, peneliti memfokuskan kajian pada peristiwa yang membuat remaja bahagia tanpa adanya kategori "others".

Data pada tabel menunjukkan bahwa kategori keluarga, mencintai dan dicintai, serta mendapatkan uang didominasi oleh responden perempuan, sedangkan kategori prestasi, spiritualitas, teman, dan waktu luang didominasi oleh responden laki-laki. Perbedaan tersebut tampak pada grafik 2 berikut :

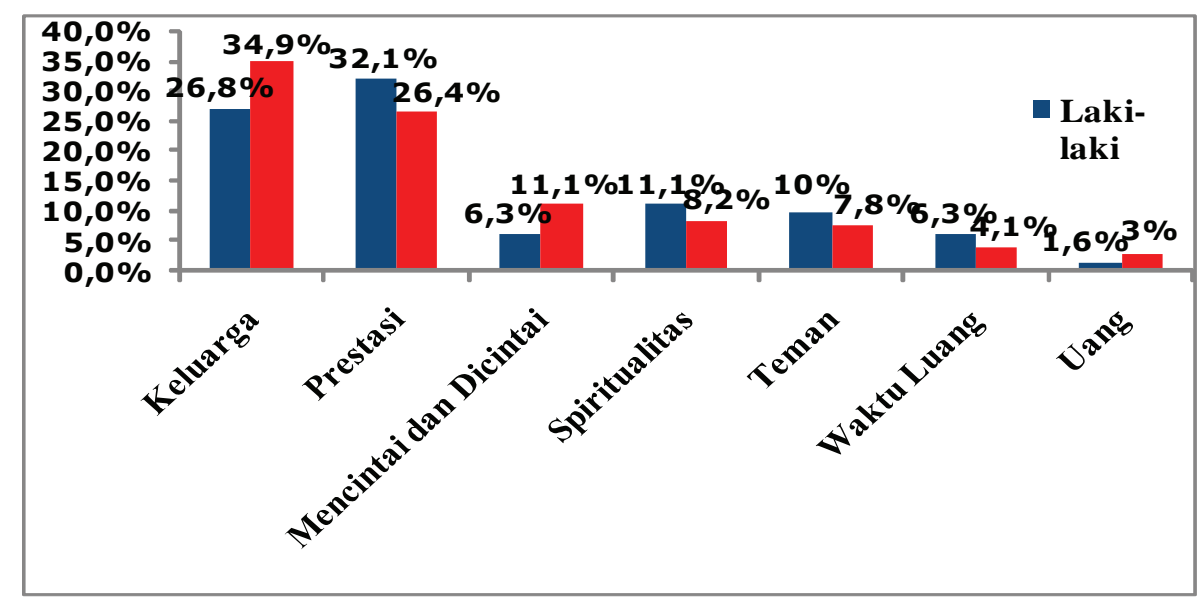

Gambar 2.Perbandingan Orientasi Kebahagiaan Siswa Laki-laki dan Perempuan

Dari grafik di atas, terlihat bahwa hasil tabulasi silang jenis kelamin dengan keluarga didominasi responden perempuan sebesar 34,9\% sedangkan responden laki-laki hanya sebesar $26,8 \%$. Kategori prestasi lebih tinggi responden laki-laki sebesar 32,1\%, sedangkan responden perempuan hanya sebesar 26,4\%. Kategori mencintai dan dicintai lebih besar responden perempuan sebesar 11,5\% dibanding $6,3 \%$ milik responden laki-laki. Kategori spiritualialitas, teman, dan waktu luang didominasi oleh responden laki-laki sebesar $11,1 \%, 10 \%$, serta $6,3 \%$ karena responden perempuan hanya sebesar $8,2 \%, 7,8 \%$, serta $4,1 \%$. Kategori terakhir, yaitu kategori uang, responden perempuan lebih tinggi yaitu sebesar $3 \%$ dibandingkan responden laki-laki yang hanya 1,6\%.

Hasil penelitian ini menunjukkan bahwa terdapat tujuh kategori peristiwa yang menyebabkan remaja merasa paling bahagia, yaitu peristiwa yang berkaitan dengan keluarga, prestasi, mencintai dan dicintai, spiritualitas, teman, waktu luang, serta uang. 
Orientasi kebahagiaan pada remaja laki-laki dan perempuan berbeda-beda (Argyle, 2001). Peristiwa yang membuat responden remaja laki-laki sangat bahagia adalah peristiwa yang berhubungan dengan prestasi, spiritualitas, teman, dan waktu luang, sedangkan pada remaja perempuan, peristiwa yang berhubungan dengan keluraga, mencintai dan dicintai, serta uang. Namun demikian, tidak terdapat perbedaan yang signifikan antara orientasi kebahagiaan remaja laki-laki dan perempuan. Tidak ada yang lebih bahagia antara remaja laki-laki dan perempuan (Compton, 2005).

\section{Simpulan}

Berdasarkan hasil penelitian di atas dapat disimpulkan bahwa tidak ada perbedaan yang signifikan kebahagiaan remaja laki-laki dan perempuan. Peristiwa yang membuat paling bahagia bagi remaja laki-laki adalah peristiwa yang berhubungan dengan prestasi, spiritualitas, teman, dan waktu luang, sedangkan bagi remaja perempuan adalah peristiwa yang berhubungan dengan kelurga, mencintai dan dicintai, serta uang.

Penelitian ini merupakan penelitian awal yang masih belum secara dalam mengkaji hubungan antara sumber dan bentuk dukungan yang diperoleh responden terhadap pembentukan orientasi kebahagiaan. Meskipun demikian, penelitian awal yang dilakukan dengan metode indigenous psychology ini setidaknya mampu mengungkap informasi yang khas dari responden. Selain itu juga diharapkan semoga penelitian ini mampu menjadi pemicu untuk dilakukannya penelitian-penelitian lanjutan yang lebih mendalam dengan menggunakan metode indigenous psychology sehingga dapat memberikan sumbangan terhadap perkembangan ilmu psikologi dan juga kemanfaatan bagi kemajuan dunia pendidikan serta kehidupan sosial.

\section{Daftar Pustaka}

Argyle, M. (2001). The Psychology of Happiness2nd ed. USA : Routledge.

Compton, W. C. (2005). An Introduction to Positive Psychology. California : Thomson Wadsworth.

Hurlock, E.B. (2004). Psikologi Perkembangan: Suatu Pendekatan Sepanjang Rentang Kehidupan Edisi Kelima. Jakarta: Erlangga.

Kim, U., \& Berry, J.W. (1993). Indigenous Psychology: Research and Experience in Cultural Contex. Volume 17, Cross Cultural Research and Methodology Series. 
Kim,U.(2009) .Indigenouspsychological analysis of trust/happiness/self/achievement/ parent-child relationship/coping with disaster. Unpublished Manucript, Inha University, Incheon, Korea.

Mappiare, A. (1982). Psikologi Remaja. Surabaya: Usaha Nasional.

Ryff, C. (1989). Happiness is everything, or is it? Explorations on the meaning of psychological well being. Journal of Personality and Social Psychology.57 (6), 1069-1081.

Shahar, T.B.(2007). Happier : Learn The Secrets to Daily Joy and Lasting Fullfillment. New york : Mc Graw Hill.

Snyder, C. R.,\& Lopez, S. J.(2006). Positive Psychology : The Scientific and Practical Explorations of Human Strengths. California Sage Publications, Inc.

Strongman, K. T. (2005). The Psychology of Emotion. England : John Willey. 